\title{
Avaliação da qualidade da água dos bebedouros da Universidade do Estado do Pará na cidade de Belém Pará, Brasil
}

Evaluation of the water quality of the drinking fountains of the Universidade do Estado do Pará in city Belém Pará, Brasil

\author{
M.P. Mendes ${ }^{1}$; N.S.G. Silva ${ }^{1}$; J.R.C. Carvalho²; J.B.P. Junior ${ }^{3}$; V.W.B. Diniz ${ }^{2 *}$ \\ ${ }^{I}$ Discentes do Departamento de Ciência Naturais, Universidade do Estado do Pará, 6650-540, Belém-PA, Brasil \\ ${ }^{2}$ Docentes do Departamento de Ciência Naturais, Universidade do Estado do Pará, 6650-540, Belém-PA, Brasil \\ ${ }^{3}$ Faculdade de Química/Grupo de Espectrometria Analítica Aplicada, Universidade Federal do Pará, 66075110, \\ Belém-PA, Brasil
}

*victor_bechir@yahoo.com.br

(Recebido em 05 de abril de 2016; aceito em 28 de abril de 2016)

\begin{abstract}
A água é um recurso de grande importância para a manutenção da vida e a sua qualidade afeta diretamente a saúde humana. Objetivou-se avaliar a qualidade da água de bebedouros da Universidade do Estado do Pará (UEPA) e verificar se está de acordo com a resolução 357/2005 do CONAMA e a portaria 2914/2011 do Ministério da Saúde. A pesquisa foi realizada nos cinco campi da UEPA na cidade de Belém Pará, Brasil. Os parâmetros físico-químicos avaliados foram: $\mathrm{pH}$, alcalinidade, acidez, ferro total, fósforo, cloreto e dureza total. Alguns resultados encontrados para $\mathrm{pH}$, que variou entre 3,92 e 7,64 mostraram valores abaixo do intervalo estabelecido pela legislação brasileira, já o elemento fósforo apresentou valores entre 0,468 e $2,671 \mathrm{mg} \mathrm{L}^{-1}$, acima dos padrões estabelecidos, mostrando que há bebedouros com águas impróprias para consumo humano.

Palavras-chave: Água, Potabilidade, Parâmetros físico-químicos.
\end{abstract}

Water is a very important resource for maintenance of life and its quality directly affects human health. This study aimed to evaluate the water quality of the drinking fountains of the Pará University State (UEPA) and verify that it is in accordance with the resolution 357/2005 of CONAMA and ordinance 2914/2011 of the Ministry of Health. The research was conducted in the five campi of UEPA in Belém, Pará, Brazil. The physicochemical parameters evaluated were: $\mathrm{pH}$, alkalinity, acidity, total iron, phosphorus, chloride and total hardness. Some results found for $\mathrm{pH}$ ranging between 3.92 and 7.64 showed values below the range established by Brazilian law. Phosphorus shows values between 0.468 and $2.671 \mathrm{mg} \mathrm{L}^{-1}$, above the established standards, showing that there are drinking fountains with water inappropriate for human consumption.

Keywords: Water, Potability, Physicochemical parameters.

\section{INTRODUÇÃO}

A água é um recurso natural de grande importância para sobrevivência do homem. Este recurso encontra-se presente em proporções elevadas na constituição de todos os seres vivos e no homem atinge cerca de $75 \%$ de sua massa corporal [1].

Desde a antiguidade as grandes cidades e civilizações se desenvolveram as margens dos rios devido à necessidade de água de qualidade, adequada e em quantidade suficiente para suprir as atividades humanas $[2,3]$.

A água doce, especificamente, que é utilizada no dia a dia do homem no meio urbano e na indústria, representa o tipo de água com menor percentual disponível no planeta Terra. Aproximadamente $97,5 \%$ da água é salgada (oceanos) e 2,5\% é doce (regiões polares, rios e 
lagos, e aquíferos subterrâneos), destes $2,5 \%$ de água doce somente $0,7 \%$ é acessível aos seres da Terra [4].

A qualidade da água é influenciada por fatores físicos, químicos e biológicos. Dentre os fatores físico-químicos estão: temperatura, cor, turbidez, $\mathrm{pH}$, alcalinidade, acidez, dureza total, substâncias químicas como ferro, chumbo, flúor, cloro, entre outros. Para o fator biológico, é comum utilizar como organismos indicadores de contaminação fecal as bactérias do grupo coliformes [5,6].

Se algum desses fatores estiver fora dos padrões de qualidade, podem acarretar riscos à saúde. Os padrões são estabelecido pela portaria 2914/2011 do Ministério da Saúde (que dispõe sobre os procedimentos de controle e de vigilância da qualidade da água para consumo humano) e pela Resolução 357/2005 do CONAMA - Conselho Nacional do Meio Ambiente (que dispõe sobre a classificação dos corpos de água e diretrizes ambientais para seu enquadramento). Os riscos estão nas doenças de veiculação hídrica, associadas, principalmente, a micro-organismos e são decorrentes do inadequado tratamento de água ou contaminação do sistema de abastecimento. [7].

Os Sistemas de Abastecimento de Água (SAA), além de objetivarem assegurar o conforto às populações e prover parte da infraestrutura das cidades, visam prioritariamente superar os riscos à saúde impostos pela água [8]. No Estado do Pará, a responsável pelo abastecimento público de água, coleta e tratamento de esgoto é a Companhia de Saneamento do Estado do Pará (COSANPA).

Neste contexto, este estudo tem como objetivo avaliar a qualidade da água, baseado em parâmetros físico-químicos, dos cinco campi da Universidade do Estado do Pará (UEPA), na capital Belém-PA. A fim de verificar se os resultados estão de acordo com os padrões estabelecidos pela Legislação Brasileira.

\section{MATERIAL E MÉTODOS}

A pesquisa foi realizada na capital Belém, Pará, nos cinco campi da UEPA, sendo eles: Centro de Ciências Sociais e Educação (CCSE), Centro de Ciências Naturais e Tecnologia (CCNT), Centro de Ciências Biológicas e da Saúde (CCBS), Enfermagem e Educação Física.

As amostras de água foram coletadas no período de 20 a 22 de maio de 2015. No campi de Enfermagem realizaram-se coletas dia 20 de maio de 2015 no horário entre 13:00 e 13:55 h, onde encontra-se 2 bebedouros. No CCSE foi no dia 20 de maio de 2015 no horário entre 15:02 e 15:16 h, há 3 bebedouros no CCSE. No dia 22 de maio de 2015 sucederam as demais coletas no campi do CCBS no horário de 08:56 e 09:39, onde há 3 bebedouros; CCNT entre 10:00 e 10:15 h com 2 bebedouros; e, campi de Ed. Física, onde coletou-se dos 3 bebedouros entre 11:00 e 11:46 h. Totalizando assim 13 pontos de coletas.

No primeiro instante, as torneiras foram higienizadas com álcool etílico $70 \%$ e em seguida, aberta em seção máxima de, aproximadamente, 2 minutos. Posteriormente, efetuou-se a coleta.

Em cada bebedouro foram coletadas amostras em recipiente de plástico de $2000 \mathrm{~mL}$ a fim de realizar análise dos parâmetros físico-químicos: $\mathrm{pH}$, alcalinidade, acidez, ferro total, fósforo, cloreto e dureza total. Após coletadas, as amostras de água foram encaminhadas para análise laboratorial em triplicata.

O abastecimento de água nos campus do CCSE e Ed. Física acontece através de poços artesianos, já no campus de Enfermagem, CCBS e CCNT através da COSANPA. No entanto, para todos os campus, a distribuição para os bebedouros acontece através de caixas d'água, que passam por um período de manutenção a cada 6 meses a 1 ano.

Para a determinação do $\mathrm{pH}$, foi transferido, aproximadamente, $50 \mathrm{~mL}$ de cada amostra para béqueres e imergiu-se o eletrodo do pHmetro (EVEN, PHS3E) para se efetuar as leituras [9].

Para determinação da alcalinidade foi transferido $100 \mathrm{~mL}$ de cada amostra para erlenmeyers e adicionou-se a solução 2 gotas de fenolftaleína, em seguida, foi adicionado às amostras 2 gotas de alaranjado de metila e titulou-se com solução-padrão de $\mathrm{H}_{2} \mathrm{SO}_{4}$ $0,02 \mathrm{~N}$, até a coloração da solução mudar de amarelo para vermelho-alaranjado [10,11].

Para determinação da acidez, foi transferido $100 \mathrm{~mL}$ de cada amostra para erlenmeyers 
de $250 \mathrm{~mL}$, adicionou-se a solução 2 gotas de fenolftaleína e titulou-se com soluçãopadrão de $\mathrm{NaOH} 0,02 \mathrm{~N}$, até adquirir coloração levemente rósea [10].

Para a determinação do ferro foi preparada uma curva de calibração de 0 a $5 \mathrm{mg} \mathrm{L}^{-1}$ à partir de uma solução estoque contendo $100 \mathrm{mg} \mathrm{L}^{-1}$ de Fe. As amostras foram preparadas conforme o seguinte procedimento: em um balão volumétrico de $100 \mathrm{~mL}$ foi adicionado $10 \mathrm{~mL}$ da solução de $\mathrm{KSCN} 20 \%, 6 \mathrm{~mL}$ de $\mathrm{HNO}_{3} 4 \mathrm{~mol} \mathrm{~L}^{-1}$ e uma alíquota de $50 \mathrm{~mL}$ da amostra. Em seguida, adicionou-se água destilada, até a marca de aferição do balão. Posteriormente, em um espectrofotômetro (NOVA, 1105) foi selecionado o comprimento de onda de $570 \mathrm{~nm}$, onde foram medidas as absorvâncias das soluções-padrão e das amostras [9].

O fósforo foi determinado preparando-se uma curva de calibração na faixa de 0 a $1 \mathrm{mg}$ $\mathrm{L}^{-1}$ à partir de uma solução estoque contendo $20 \mathrm{mg} \mathrm{L}^{-1}$ de $\mathrm{P}$. Para preparação das amostras, alíquotas de $25 \mathrm{~mL}$ de cada amostra foram transferidas para balões volumétricos de $50 \mathrm{~mL}$ e, em seguida, foi adicionado $10 \mathrm{~mL}$ da solução de molibdato de amônio e uma porção de ácido ascórbico. Após isso, as amostras foram deixadas em repouso por $1 \mathrm{~h}$ para que ocorresse desenvolvimento da cor. Após este tempo, as leituras das absorvâncias das soluções-padrão e das amostras foram realizadas usando um espectrofotômetro com comprimento de onda de $690 \mathrm{~nm}$ [11].

Para a realização da determinação de cloretos foi transferido $100 \mathrm{~mL}$ de cada amostra para erlenmeyers, onde foi adicionado $0,5 \mathrm{~mL}$ do indicador $\mathrm{K}_{2} \mathrm{CrO}_{4} \mathrm{e}$, em seguida, titulouse com solução-padrão de $\mathrm{AgNO}_{3}$ 0,1 mol/L, até a mudança de coloração de amarelo citrino para vermelho tijolo [10].

Para a determinação da dureza total, $100 \mathrm{~mL}$ de cada amostra foi transferida para erlenmeyers, onde foram adicionadas 5 gotas de $\mathrm{HCl}$ concentrado, $10 \mathrm{~mL}$ de trietanolamina (1:1), 12,5 mL de amônia e o indicador EBT. Após isso, as amostras foram tituladas com solução-padrão de $\mathrm{Na}_{2}$ EDTA $0,025 \mathrm{~N}$ até a mudança de coloração rósea para azul nítido [9].

Para a determinação da dureza cálcica, $100 \mathrm{~mL}$ de cada amostra foi transferida para erlenmeyers, onde foi adicionado $2,5 \mathrm{~mL}$ de trietanolamina (1:1), $5 \mathrm{~mL}$ de $\mathrm{NaOH} 25 \%$ e uma pequena porção do indicador Calcon. As amostras foram tituladas com soluçãopadrão de $\mathrm{Na}_{2}$ EDTA $0,025 \mathrm{~N}$ até a mudança de coloração vermelho-violáceo para azul [9].

Para se determinar a dureza magnesiana foi usado um método indireto que consiste na diferença entre a dureza total e a dureza cálcica (Dureza $\left[\mathrm{Mg}^{2+}\right]=$ dureza total - dureza $\left.\left[\mathrm{Ca}^{2+}\right]\right)[9]$.

\section{RESULTADOS E DISCUSSÃO}

Com base nas análises referentes à qualidade da água, a tabela a seguir apresenta os valores médios obtidos:

Tabela 01: Resultados das análises físico-químicas da água

\begin{tabular}{ccccccc}
\hline & & \multicolumn{5}{c}{ Campi } \\
\hline \multirow{2}{*}{ Parâmetro } & $\begin{array}{c}\text { Bebe- } \\
\text { douro }\end{array}$ & CCSE & CCBS & $\begin{array}{c}\text { Educação } \\
\text { Física }\end{array}$ & Enfermagem & CCNT \\
\hline & $\mathrm{B}_{1}$ & 4,04 & 6,57 & 6,69 & 7,22 & 7,26 \\
$\mathrm{pH}$ & & $\pm 0,09$ & $\pm 0,09$ & $\pm 0,10$ & $\pm 0,12$ & $\pm 0,11$ \\
& $\mathrm{~B}_{2}$ & 4,28 & 7,03 & 6,20 & 7,64 & 7,10 \\
& & $\pm 0,08$ & $\pm 0,10$ & $\pm 0,09$ & $\pm 0,11$ & $\pm 0,10$ \\
& $\mathrm{~B}_{3}$ &, \pm 92 & 7,34 & 6,16 & - & - \\
Alcalinidade & $\mathrm{B}_{1}$ & Ausente & Ausente & Ausente & 3,719 & 3,403 \\
(mg L L $^{-1}$ de & & & & & $\pm 0,099$ & $\pm 0,110$ \\
\hline
\end{tabular}




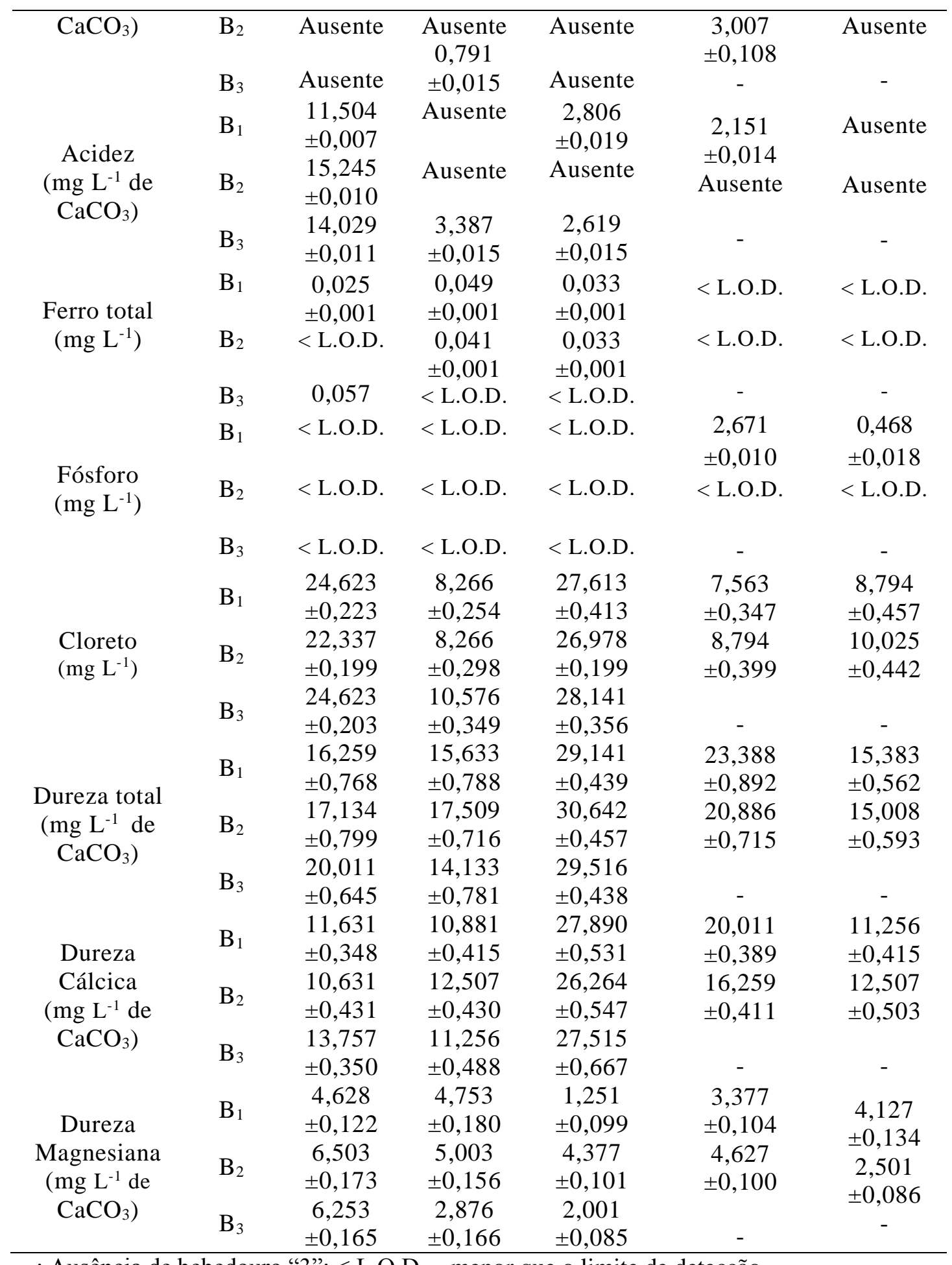

-: Ausência de bebedouro "3"; < L.O.D. - menor que o limite de detecção.

Os valores de $\mathrm{pH}$ encontrados nas amostras variaram de 3,92 a 7,64. O pH na maioria das amostras analisadas encontram-se dentro do estabelecido pela Portaria $n^{\circ} 2914 / 11$ do MS [12], que define o pH padrão no intervalo de 6,0 a 9,5. As amostras dos bebedouros do CCSE apresentaram valores de $\mathrm{pH}$ no intervalo de 3,92 a 4,28. Um pH ácido tende a comprometer a conservação de tubulações e equipamentos, assim como causar a precipitação de agentes bacterianos [13]. As alterações de $\mathrm{pH}$ no CCSE podem ser decorrentes do tipo de fonte de abastecimento de água, através de poço artesiano, tendo em vista que os outros campi da Universidade são abastecidos pela Companhia de Saneamento do Pará (COSANPA). No entanto, o campi de Educação Física que possui abastecimento também por poço artesiano, 
apresentou- valores de $\mathrm{pH}$ próximo de 7 (Tabela 01). Assim, é provável que a diferença de $\mathrm{pH}$ entre os campi CCSE e Educação Física seja em função da natureza dos solos, que podem ser naturalmente ácidos em função da pobreza em bases do material de origem ou devido a processos de formação que favorecem a remoção de elementos básicos como $\mathrm{K}, \mathrm{Ca}, \mathrm{Mg}$ e $\mathrm{Na}$ [14].

Os valores de alcalinidade variaram de 0,791 a $3,719 \mathrm{mg} \mathrm{L}^{-1}$ de $\mathrm{CaCO}_{3}$. A alcalinidade pode apenas conferir alterações no paladar e causar a rejeição da água; assim, a ausência ou o excesso desta variável não oferece riscos mais graves $[15,16]$. Observou-se que durante as análises as amostras permaneceram incolores para o indicador fenolftaleína, o que sugere ausência de alcalinidade devido o íon hidroxila $\left(\mathrm{OH}^{-}\right)[10,11]$.

Para acidez, os valores variaram no intervalo de 2,151 a $15,245 \mathrm{mg} \mathrm{L}^{-1}$ de $\mathrm{CaCO}_{3}$. O campi CCSE apresentou valores mais elevados para a acidez da água, variando entre 11,504 a 15,245 $\mathrm{mg} \mathrm{L}^{-1}$ de $\mathrm{CaCO}_{3}$. A Fundação Nacional de Saúde - FUNASA (2014) [17] aponta que águas com acidez elevada são desagradáveis ao paladar. Além disso, a acidificação das águas é capaz de promover doenças crônicas como diabetes mellitus, cânceres e induzir a acidose metabólica, causadas pela carência na concentração de carbonatos na água $[18,19,20]$.

Para o parâmetro ferro total, os valores obtidos foram entre 0,025 a $0,057 \mathrm{mg} \mathrm{L}^{-1}$. Sendo assim, todas as amostras encontram-se dentro do padrão estabelecido pela Portaria $\mathrm{n}^{\circ}$ 2914/11 do MS [12], que adota um valor máximo permitido (VMP) de $0,3 \mathrm{mg} \mathrm{L}^{-1}$. A presença de ferro, dependendo das concentrações, pode propiciar uma coloração amarelada e turva à água e acarretar sabor amargo e adstringente [21]. O limite de detecção (L.O.D), que é a menor concentração de uma substância que pode ser detectada na amostra e que se distingue do zero, foi calculada e para o ferro encontrado o valor de $0,0181 \mathrm{mg} \mathrm{L}^{-1}$ [22].

Em relação ao parâmetro fósforo, os B1 do campi CCNT e do campi de Enfermagem tiveram concentrações de $0,468 \mathrm{mg} \mathrm{L}^{-1}$ e $2,671 \mathrm{mg} \mathrm{L}^{-1}$, respectivamente, apresentando teores

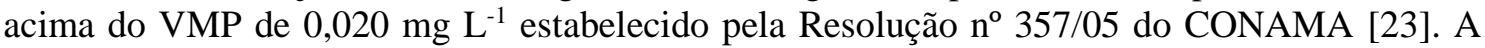
maioria das amostras apresentaram valores abaixo do limite de detecção (L.O.D) que foi de $0,0040 \mathrm{mg} \mathrm{L}^{-1}$ [22]. Essas alterações nestes dois bebedouros que apresentaram teor elevado de fosforo, podem ser decorrentes da limpeza dos bebedouros que fora realizada pelos funcionários com detergente, minutos antes da coleta. Os detergentes, além dos surfactantes, apresentam fosfato em sua composição, no entanto, os teores encontrados não representam perigo de toxicidade aos seres vivos $[24,25]$.

Com relação ao parâmetro cloreto, os valores encontrados variaram de 7,563 a $28,141 \mathrm{mg} \mathrm{L}^{-}$ 1, apresentando-se de acordo com a Portaria $n^{\circ} 2914 / 11$ do MS [12], que estabelece um VMP de $250 \mathrm{mg} \mathrm{L}^{-1}$ de cloreto. Altas concentrações de cloretos podem restringir o uso da água em razão do sabor que conferem e pelo efeito laxativo que podem provocar [26].

Com base nas análises para a dureza total, os valores obtidos encontram-se no intervalo de 14,133 a 30,516 $\mathrm{mg} \mathrm{L}^{-1}$ de $\mathrm{CaCO}_{3}$, apresentando-se dentro do exigido pela Portaria $\mathrm{n}^{\mathrm{o}}$ 2.914/11

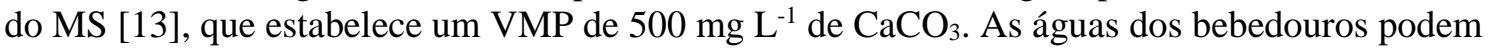
ser classificadas, de acordo com o grau de dureza, em branda ou mole, pois a concentração se estabelece inferior a $50 \mathrm{mg} \mathrm{L}^{-1}$ de $\mathrm{CaCO}_{3}$ [15]. A dureza total refere-se à concentração total de íons, principalmente, de cálcio e magnésio provenientes de minérios que em contato com a água

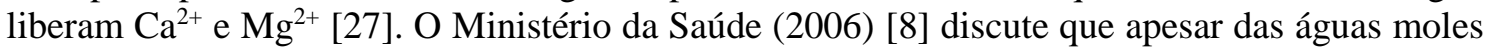
não provocarem incrustações nas tubulações, elas podem estar relacionadas com doenças cardíacas, haja vista que as águas duras contribuem para uma menor incidência de doenças cardiovasculares.

\section{CONCLUSÕES}

Com os resultados obtidos, segundo os parâmetros físico-químicos analisados, pode-se inferir que os parâmetros $\mathrm{pH}$ do CCSE está em desacordo com os padrões exigidos pela Portaria $\mathrm{n}^{\circ}$ 2914/11 do MS. Águas destinadas para consumo humano que apresentam um baixo pH, podem causar contaminação microbiana e comprometer a saúde de quem a consome 
Os resultados encontrados para o fósforo dos B1 do CCNT e campi de Enfermagem, foram comparados com a Resolução $\mathrm{n}^{\circ}$ 357/05 do CONAMA e estes se mostraram em desacordo.

Apesar de o parâmetro fósforo ter se apresentado elevadas concentrações nos bebedouros e campi já mencionados, o mesmo não apresenta toxicidade ao organismo humano.

Sendo assim, as amostras de água dos bebedouros do CCSE, B1 do CCNT e campi de Enfermagem, encontram-se impróprias para consumo humano. Os demais bebedouros encontram-se em conformidade com os padrões estabelecidos pelo MS e CONAMA.

É importante a análise dos parâmetros de qualidade das águas dos bebedouros constantemente, uma vez que estes atendem um grande público. Estas análises são importantes para a comunidade consumidora pois alerta sobre a qualidade do produto oferecido.

\section{REFERÊNCIAS BIBLIOGRÁFICAS}

1. Lemos JC, Flauzino, FS, Silva, JB, Ferrete, JA, Rezende, K. Qualidade da água utilizada pelos moradores do assentamento de reforma agrária Bom Jardim, no município de Araguari - Minas Gerais, Brasil. In: $26^{\circ}$ Congresso Brasileiro de Engenharia Sanitária e Ambiental; 2011 Set 25-29; Porto Alegre, RS. 2011.

2. Silveira T. Análise Físico-química da água da bacia do rio cabelo - João Pessoa - PB. In: II Congresso de Pesquisa e Inovação da Rede Norte Nordeste de Educação Tecnológica, 2007.

3. Endler DTK, Nogueira PC, Santana VS, Fiorese ML, Hasan SDM. Avaliação da Qualidade da Água de Irrigação Utilizada em Propriedades Rurais do Município de Toledo-PR. In: III Encontro Paranaense de Engenharia e Ciência, 2013 Out 28-30; Toledo PR; 2013. p. 45.

4. Tundisi JG. Água no século XXI: Enfrentando a Escassez. 2. Ed. São Carlos: RiMa, 2005. p. 228.

5. Ciminelli VST, Barbosa FAR, Tundisi JG, Duarte HA. Recursos Minerais, Água e Biodiversidade. Química Nova na Escola, mai. 2014. p.39-45, doi: 10.5935/0104-8899.20160002.

6. Secretaria Nacional de Saneamento Ambiental (org.). Operação e manutenção de estações: abastecimento de água: guia do profissional em treinamento: nível 1/. - Belo Horizonte: ReCESA, 2007.

7. Texeira JC, Leal, FCT. Desafios no Controle de Doenças de Veiculação Hídrica Associadas ao Tratamento e ao Abastecimento de Água para Consumo Humano. In: VI Simpósio Ítalo Brasileiro de Engenharia Sanitária e Ambiental, 2002, Set 3-5; Vitória ES; 2002. p.1-5.

8. Brasil. Ministério da Saúde. Vigilância e Controle da Qualidade da Água para Consumo Humano. Brasília, 2006.

9. Vogel, AI. Análise inorgânica quantitativa. Rio de Janeiro: Guanabara Dois SA. 1981

10. Ohlweiler OA. Química Analítica Quantitativa. vol 2 e 3 Rio de Janeiro; Livros Técnicos e Científicos; Brasília INL, 1974.

11. Clesceri LS, Greenberg A, Ealton AD. (Edit). Standard methods: for the examination of water and wastewater. 20 ed. Washington: American Public Health Association, 1998.

12. Brasil. Ministério da saúde. Portaria $n^{\circ}$ 2.914/2011: Controle e vigilância da qualidade da água para consumo humano e seu padrão de potabilidade. Brasília: Editora do Ministério da Saúde, 2011.

13. Barros MS, Pfal LA, Oroski FI. Análise da Qualidade da Água em Estabelecimentos Leiteiros Associados da Cooperativa Agropecuária Batavo - Carambeí - PR. Biblioteca Virtual Emater, 2006.

14. Lopes AS, Silva MC, Guilherme LRG. Boletim Técnico n 1 Acidez do Solo e Calagem. Associação Nacional para Difusão de Adubos. São Paulo - SP, 1991.

15. Vasconcelos VMM, Souza CF. Caracterização dos parâmetros de qualidade da água do manancial Utinga, Belém, PA, Brasil. Revista Ambiente \& Água - An Interdisciplinary Journal of Applied Science: 2006. p.305-324, doi: 10.4136/1980-993X.

16. Bastos ML. Caracterização da Qualidade da Água Subterrânea: Estudo de Caso no Município de Cruz das Almas - Bahia. [Monografia de Graduação]. Tese - Universidade Federal do Recôncavo da Bahia, Centro de Ciências Exatas e Tecnológicas. Cruz das Almas; 2013. 78p.

17. Brasil. Ministério da Saúde. Fundação Nacional de Saúde. Manual de controle da qualidade da água para técnicos que trabalham em ETAS / Ministério da Saúde, Fundação Nacional de Saúde. - Brasília : Funasa, 2014.

18. Souza ES, Cardoso Junior JCA. Análise da qualidade da água. In: VI Encontro de Recursos Hídricos em Sergipe. 2013 Fev 20; Aracaju, SE; 2013. p. 2.

19. Konner M, Eaton SB. Nutrition in Clinical Practice. Paleolithic Nutrition. Twenty-Five Years Later, 2010. p.594-602 
20. Robey IF, Nesbit LA. Investigating mechanisms of alkalinization for reducing primary breast tumor invasion. Biomed Research International. Arizona Respiratory Center, University of Arizona. Epub. 2013

21. Fernandez FRD, Di Souza L. Quantificação dos teores de Sulfato e Ferro nas águas subterrâneas do oeste do Rio Grande do Norte. In: I Encontro Regional de Química: Ciência, Tecnologia e Sociedade. 2011 Nov 28- Dez 02; Mossoró RN; 2011.

22. Skoog DA, West DM, Holler FJ, Crouch SR. Fundamentos de Química Analítica. São Paulo: Cengage Learning, 2011.

23. Conama-Conselho Nacional do Meio Ambiente. Resolução n ${ }^{\circ}$ 357, de 17 de março de 2005. Ministério do Meio Ambiente; 2005. p. 58-63.

24. Galão OF, Bueno EAS, Borsato D, Almeida, FAZ, Moreira I, Martins A. A química no ensino médio tendo "detergente" como tema motivador. Semina: Ciências Exatas e Tecnológicas, 2003 Dez; Londrina PR; 2003. p. 85-92.

25. Silva SAP. Biorremediação em águas residuais: remoção de fosfatos utilizando microalgas Chlorella vulgaris imobilizadas em meio de alginato de sódio. [Dissertação de Mestrado]. Tese - Faculdade de Ciências da Universidade do Porto; 2007. 75p.

26. da Cruz JN, Clain AF. A Interferência do pH na Análise de Cloreto pelo Método de Mohr. Revista Eletrônica TECCEN, Vassouras; 2010. p. 29-44.

27. Abdalla KVP, Cavalcante PRS, Costa Neto JP, Barbieri R, de Mesquita Neto MC. Avaliação da Dureza e das Concentrações de Cálcio e Magnésio em Águas Subterrâneas da Zona Urbana e Rural do Município de Rosário-MA. In: XVI Congresso Brasileiro de Águas Subterrâneas e XVII Encontro Nacional de Perfuradores de Poços, 2010 Ago 30- Set 03; São Luiz,MA; 2010. p.1-11. 